\title{
Long-term results of osteochondral autograft transplantation of the talus with a novel groove malleolar osteotomy technique
}

\author{
Berkin Toker, $\mathrm{MD}^{1}{ }^{\mathbb{D}}$, Tunay Erden, $\mathrm{MD}^{1}{ }^{\mathbb{D}}$, Sarper Çetinkaya, $\mathrm{MD}^{1}{ }^{\mathbb{D}}$, Göksel Dikmen, $\mathrm{MD}^{2} \mathbb{D}^{\mathbb{D}}$, \\ Vahit Emre Özden, MD²D, Ömer Taşer, MD'1D \\ ${ }^{1}$ Department of Orthopedics and Traumatology, Acıbadem Fulya Hospital Sports Medicine Center, Istanbul, Turkey \\ ${ }^{2}$ Department of Orthopedics and Traumatology, Acıbadem Maslak Hospital, Istanbul, Turkey
}

Osteochondral lesions of the talus (OLT) are frequently observed in orthopedic practice, and these defects are primarily caused by a single or recurrent traumatic event. ${ }^{[1]}$ There are numerous treatment options defined in the literature. Bone marrow stimulation techniques are generally preferred for smaller lesions, while for larger lesions, osteochondral autograft transfer (OAT) or autologous chondrocyte implantation (ACI) may be preferable. ${ }^{[2]}$ Due to high costs and difficulty in obtaining the allograft and the two-stage procedure of the ACI procedure, the OAT procedure is advantageous for larger talar lesions.

The autologous osteochondral transfer method has been reported to have good to excellent results. ${ }^{[3-6]}$ The OAT method for the talus is a challenging method

Received: April 06, 2020

Accepted: June 25, 2020

Published online: September 11, 2020

Correspondence: Tunay Erden, MD. Acıbadem Fulya Hastanesi Spor Hekimliği Merkezi, Ortopedi ve Travmatoloji Bölümü,

34349 Beşiktaş, İstanbul, Türkiye.

E-mail: doktorerden@hotmail.com

Doi: 10.5606/ehc.2020.75231

Citation: Toker B, Erden T, Çetinkaya S, Dikmen G, Özden VE, Taşer Ö. Long-term results of osteochondral autograft transplantation of the talus with a novel groove malleolar osteotomy technique. $\mathrm{Jt}$ Dis Relat Surg 2020;31(3):509-515.

(C2020 All right reserved by the Turkish Joint Diseases Foundation

This is an open access article under the terms of the Creative Commons Attribution-NonCommercial License, which permits use distribution and reproduction in any medium, provided the original work is properly cited and is not used for commercial purposes (http://creativecommons.org/licenses/by-nc/4.0/).

\section{ABSTRACT}

Objectives: This study aims to evaluate the long-term results of osteochondral autograft transfer (OAT) of talar lesions performed using a modified osteotomy technique.

Patients and methods: This retrospective study included 20 consecutive patients (11 males, 9 females; mean age $33.5 \pm 11$ years; range, 15 to 56 years) ( 21 ankles) with osteochondral lesions of the talus (OLT) treated with the OAT system between August 2002 and October 2008. We performed a modified sulcus groove osteotomy, which provides better exposure of medial and central lesions. After a minimum duration of 10 years following surgery, patients' clinical functions were evaluated according to the American Orthopaedic Foot and Ankle Society (AOFAS) anklehindfoot scale and visual analog scale (VAS). The Tegner-Lysholm scoring system was used to determine the levels of knee activity.

Results: The mean follow-up period was 143.5 (range, 120 to 186) months. The mean AOFAS scores significantly improved from $60.4 \pm 7.4$ (range, 48 to 70 ) preoperatively to $86.2 \pm 9.23$ (range, 60 to 94$)$ at the last follow-up $(\mathrm{p} \leq 0.05)$. The mean ankle VAS score significantly decreased from $6.3 \pm 0.4$ (range, 5 to 7 ) preoperatively to $2.0 \pm 1.4$ (range, 0 to 4 ). The mean Tegner-Lysholm score for this group was $89.7 \pm 11.7$ (range, 68 to 100). Revision surgery was performed in only two patients because of impingement and arthritis. Recurrent knee pain at the donor site of the osteochondral autograft was observed in three patients (14\%).

Conclusion: In the present study, good to excellent results were obtained in the treatment of OLT with OAT for a minimum follow-up duration of 10 years. This novel technique can also simplify the steep learning curve, which is challenging for surgeons.

Keywords: Malleolar osteotomy, mosaicplasty, osteochondral autograft transfer, osteochondral lesion, talus.

because the operative technique is associated with a steep learning curve and donor site morbidity in the knee joint. Several previous studies that used the Osteochondral Autograft Transfer System (Arthrex, Naples, Florida) showed excellent results in the knee 
joint over long follow-up periods. ${ }^{[4]}$ However, few published studies have reported use of the technique for OLT. A few recent studies have reported the results of long-term outcomes. ${ }^{[7-10]}$ To the best of our knowledge, the present study provides the longest follow-up series reported in the literature. We also preferred a novel groove malleolar osteotomy, which provides better approach, particularly in central and large medial lesions. Therefore, in this study, we aimed to evaluate the long-term results of OAT of talar lesions performed using a modified osteotomy technique.

\section{PATIENTS AND METHODS}

Medical records of a group of 24 consecutive patients with OLT who were performed OAT with a classic malleolar osteotomy combined with a groove osteotomy at Acrbadem Fulya Hospital between August 2002 and October 2008 were retrospectively analyzed. All patients had symptomatic ankle joint pain and limitations in physical activity (sports or daily living) despite having undergone a minimum of six months of non-surgical treatment. Patients who had functional scores and radiological evaluations for at least 10 years of follow-up were included the study. The exclusion criteria were: lesions smaller than $0.5 \mathrm{~cm}^{2}$, kissing lesions, lateral lesions, generalized chondropathy, infection, Takakura stage I-IV osteoarthritis, rheumatoid arthritis, metabolic diseases and hindfoot deformities with a need of correction. In addition, patients who did not have pre- and postoperative scores or did not continue the follow-up period were excluded (four patients, including two who did not have functional scores and radiological evaluations for at least 10 years of follow-up and two who did not have preoperative scores). Finally, 20 patients (11 males, 9 females; mean age $33.5 \pm 11$ years; range, 15 to 56 years) (21 ankles) were included in the study. Two patients previously underwent arthroscopic debridement, one previously underwent failed open fixation of the osteochondral lesion with bioabsorbable screws, and one patient underwent retrograde drilling for osteochondral lesion. Concomitant ankle lateral instability was detected in two patients: one had undergone Broström reconstruction, and one had undergone primary anterior talofibular ligament repair with suture anchors. All patients had full range of motion of the ankle joint preoperatively. Preoperative magnetic resonance imaging (MRI) scans were used to determine the lesion type, site, and size and the presence of subchondral cysts and concomitant pathologies. Nineteen patients had medial lesions, and two had central lesions. The
Bristol classification system was used to determine lesion type. ${ }^{[1]}$ The study protocol was approved by the Acibadem University Institutional Review Board (No: 2020-12/32) and the requirement for informed consent was waived. The study was conducted in accordance with the principles of the Declaration of Helsinki.

Routine clinical and radiological follow-up examinations were performed at 2, 6, 12, 24 weeks and one year. After first year, the patients were called up for control once a year. Patients' clinical functions were evaluated pre- and postoperatively at the last follow-up (min 10 years) according to the American Orthopaedic Foot and Ankle Society (AOFAS) ankle-hindfoot scale. Pain was assessed with the visual analog scale (VAS). The TegnerLysholm activity scale was used to determine the degree of return to sports and activity performance. An arthritis evaluation was also performed using standing anteroposterior and lateral radiographs according to the Takakura Radiologic Arthritis Classification System. ${ }^{[12]}$

After the classic malleolar oblique osteotomy $\left(30^{\circ}\right.$ to $45^{\circ}$ to the joint line) was performed with an

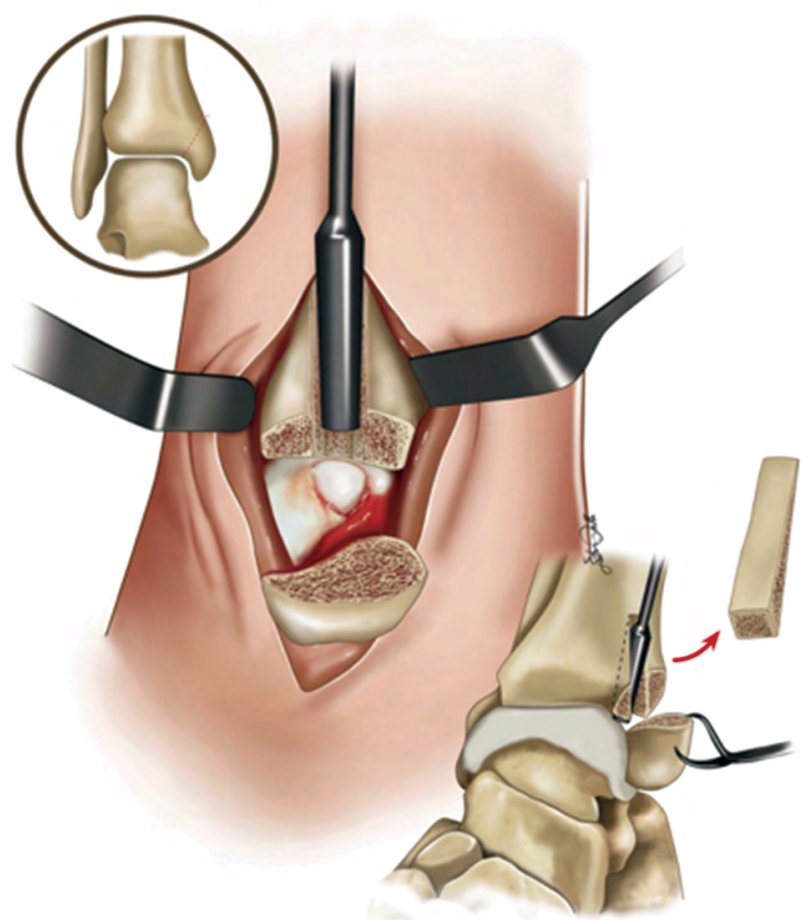

FIGURE 1. Stages of modified medial malleolar osteotomy technique.

Red arrow: Removal of triangular prism-shaped bone block and oblique view of transfer of osteochondral autograft transfer plug. Black circle: Red dotted line shows oblique medial malleolar osteotomy line. 
oscillating saw, the periosteum was cut and elevated in a T-shape in the remaining plafond tibia. To enable improved osteosynthesis of the medial malleolus, the medial malleolus was predrilled for $4.5 \mathrm{~mm}$ cannulated screws before the malleolar osteotomy was performed. A secondary groove osteotomy in a triangular prism shape was performed using an osteotome from the middle of the tibia plafond to reach the lesion at a vertical angle. The bone block was removed. By plantar flexing and everting the ankle, the medial or central talar lesions were reached at an adequate angle regardless of the size of the defect (Figures 1 and 2a-e).

This method provides better exposure of the talus, better handling of the recipient tool, and accurate insertion of the plug. The osteochondral plug, which is taken from the medial femoral condyle of the ipsilateral knee, is inserted, and the triangular block is fixed to its original location without a fixation device. The medial malleolar osteosynthesis is created by inserting two $4.5 \mathrm{~mm}$ cannulated screws in the predrilled holes, and the periosteum is sutured over the tibia (Figures 3 and 4).

\section{Statistical analysis}

The descriptive statistics were calculated as the mean \pm standard deviation. The principal dependent variables of the clinical outcomes were the VAS, AOFAS, Tegner-Lysholm scores at the last follow-up. Improvement in preoperative functions and the last control values were evaluated using a paired t-test. The statistical analysis was conducted using the SPSS version 13.0.1 software (SPSS Inc., Chicago, IL, USA), and significance was defined as $\mathrm{p} \leq 0.05$.
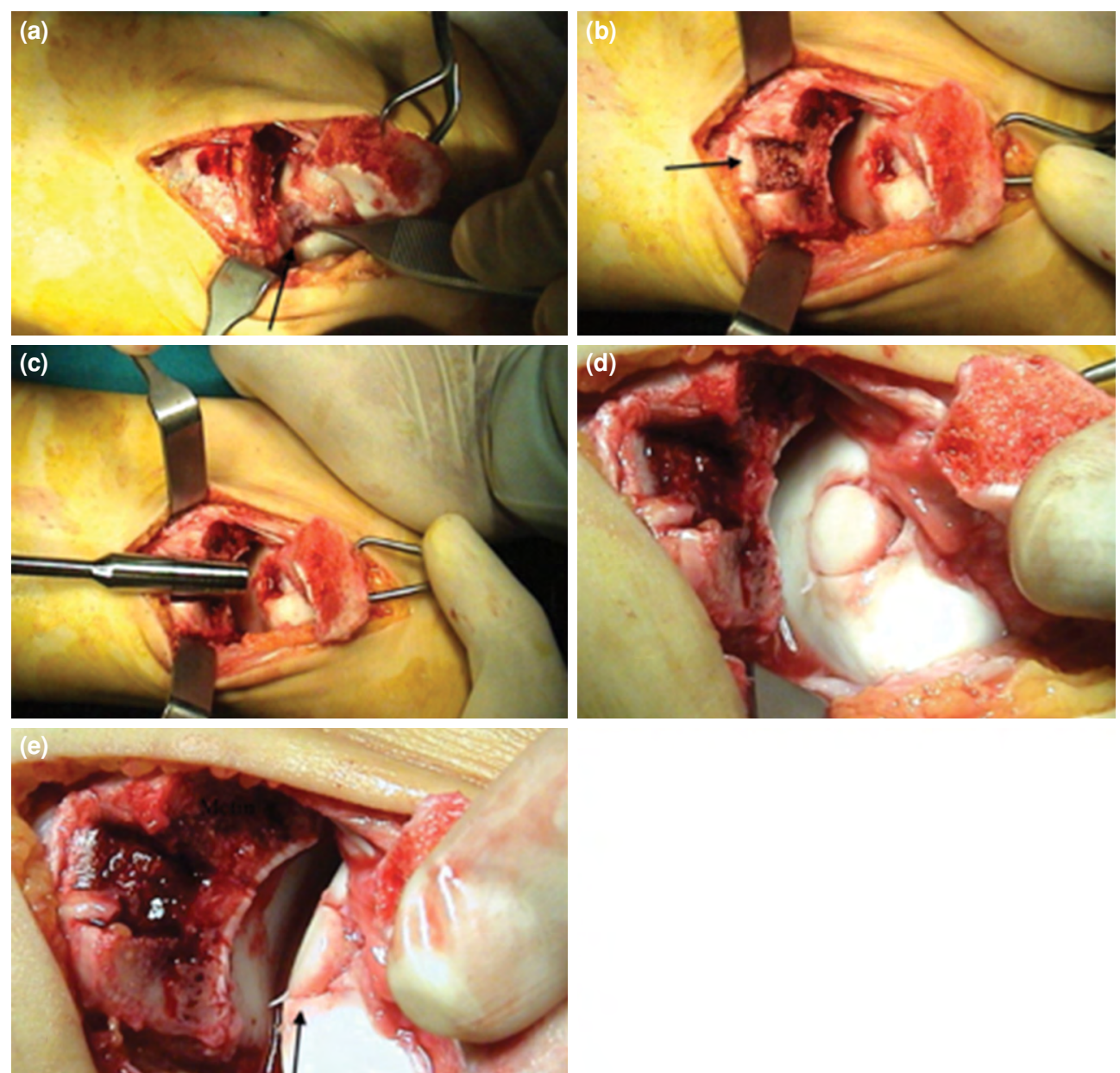

FIGURE 2. (a) Perioperative pictures of talar lesion area (black arrow) after malleolar osteotomy is performed. (b) Black arrow shows sulcus after groove osteotomy is performed. (c) Demonstration of ability to have an adequate angle to reach lesion. (d) Visualization of area after implantation of osteochondral plug. (e) Black arrow shows joint congruency in lateral view after implantation of osteochondral autograft transfer plug. 


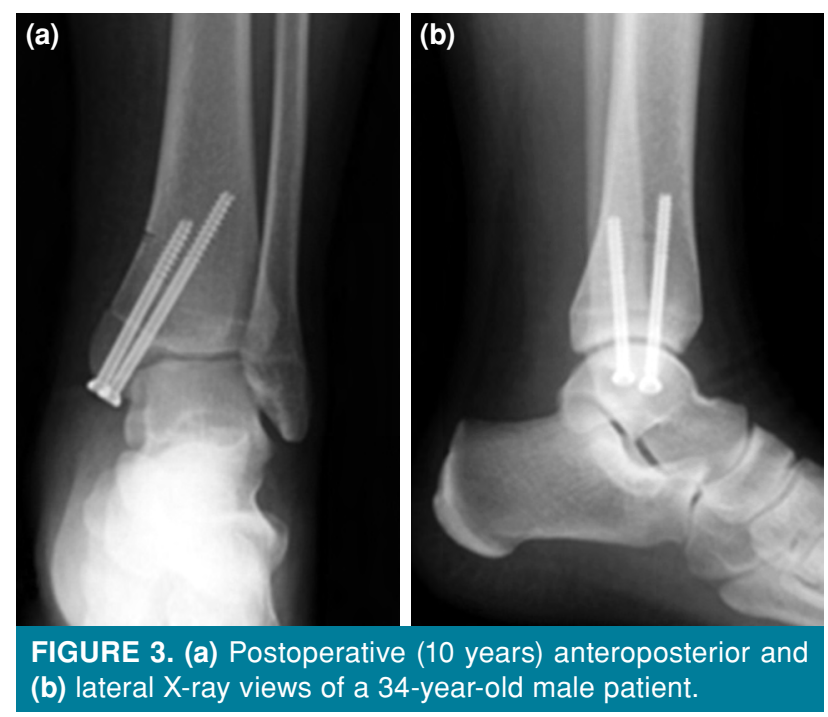

\section{RESULTS}

According to the radiology reports and Bristol classification, type 3 was identified in 12 (57\%) ankles, type 4 was identified in seven $(33.3 \%)$ ankles, and type 5 was identified in two $(9.6 \%)$ ankles.

Among the 20 patients, one was a professional athlete, and 19 patients performed regular sports activities two or three times a week. The mean followup period was 143.5 (range, 120 to 186) months. The average AOFAS score significantly improved from $60.4 \pm 7.4$ (range, 48 to 70 ) preoperatively to $86.2 \pm 9.2$ (range, 60 to 94 ) at the last follow-up ( $\leq 0.05$ ). The mean ankle VAS score significantly decreased from $6.3 \pm 0.4$ (range, 5-7) preoperatively to $2.0 \pm 1.4$ (range, $0-4)$ (Table I). Only two (9.5\%) patients underwent revision after the OAT. In $10(47 \%)$ ankles, double plugs were inserted due to a large defect.

Second-look arthroscopy was performed in one patient due to anterior ankle impingement and in two patients due to unexplained pain. The implant was removed in two of these patients due to local irritation of the screw heads. In the ankle impingement case, seven years after an OAT operation, osteophytes originating from the tibia were resected arthroscopically. The graft was intact with minimal softening. In the other two secondlook cases, the OAT borders were barely perceptible, and the surrounding cartilage was fully integrated. The mean Tegner-Lysholm score was 89.7 (range, 68 to 100), and recurrent knee pain at the donor site of the osteochondral autograft was observed in three (14\%) patients.

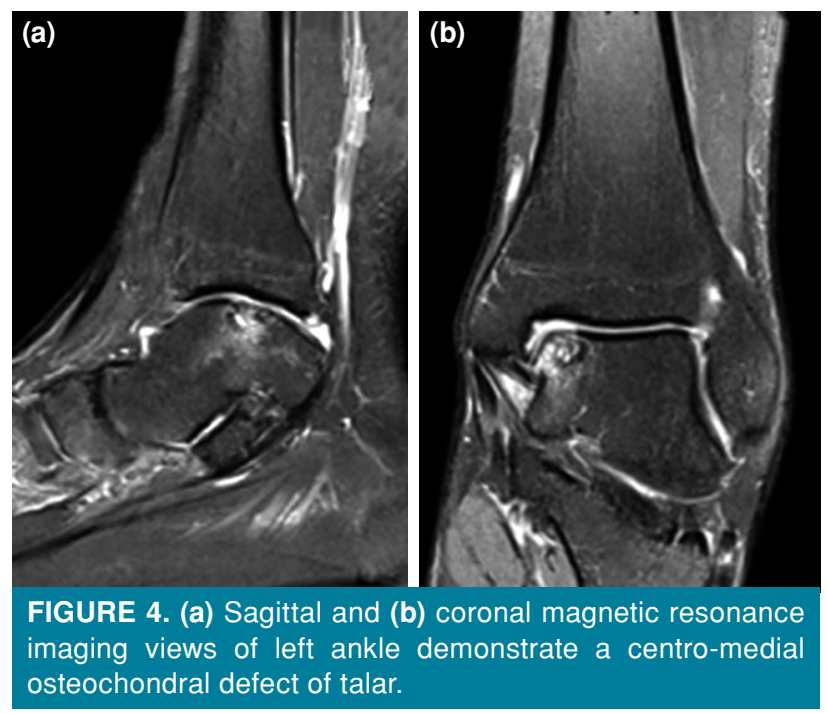

Radiological assessments of arthritis revealed that one patient had grade IIIA lesion and two had grade I arthritis according to the Takakura Radiologic Classification System, and arthrodesis was performed for the patient with grade IIIA lesion after six years because of recurrent pain and arthritis.

\section{DISCUSSION}

In the surgical treatment of OLT, there are no specific guidelines. Patient's age, activity level, lesion size, subchondral bone status, cyst formation and surgeon's experience were all variable factors. ${ }^{[2]}$ To achieve hyaline cartilage and optimum clinical results, OAT or mosaicplasty is one of the most preferable treatment options. ${ }^{[13]}$

To the best of our knowledge, compared with the literature, this study utilized the longest followup period in an ankle OAT cohort. Imhoff et al. ${ }^{[5]}$ reported an average follow-up period of seven years in a study with 25 patients, and Valderrabano et al. ${ }^{[9]}$ reported a mean follow-up period of 72 months in a study with 12 patients.

Our clinical results are similar to those of previous studies that conducted alternative operative techniques. Approximately $90 \%$ of the patients showed excellent outcomes in our study over the long-term follow-up period. Hangody et al., ${ }^{[14]}$ who were the first to publish a study on OAT on talar lesions, reported that $94 \%$ of the 36 patients showed good to excellent results. Lee et al. ${ }^{[6]}$ also found good to excellent results in all patients in a follow-up period of 36 months. In contrast, Valderrabano et al. ${ }^{[9]}$ reported moderate results in the 21 patients included in their study over 


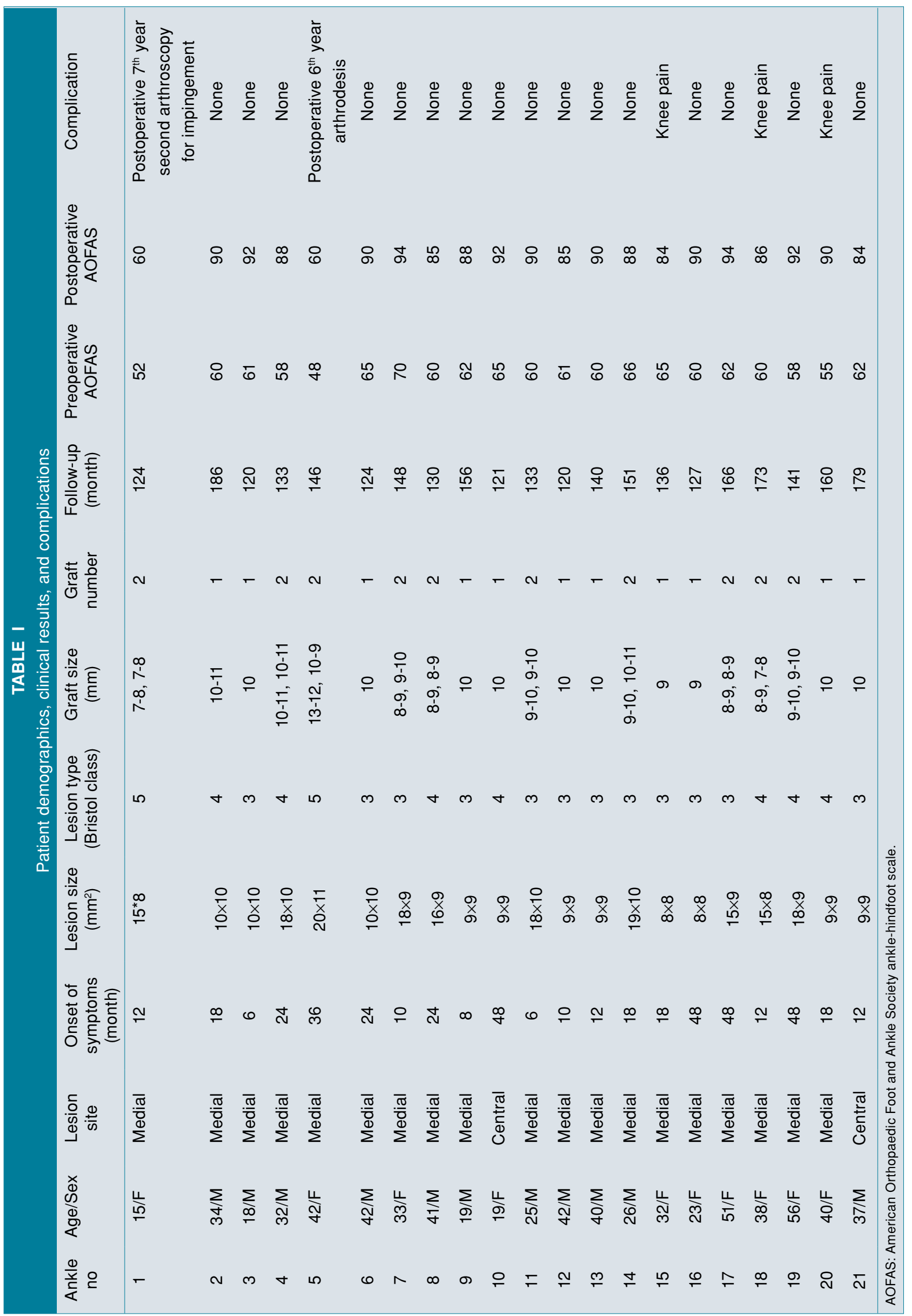


a follow-up period of 72 months. Although $92 \%$ of the patients' short-term results were good to excellent, the authors found moderate results for the reduction of ankle dorsiflexion. Common ankle OAT yielded satisfactory results despite the technically demanding procedure that it requires.

In some cases, such as large medial lesions and central lesions, this approach was not adequate; therefore, there was a need for additional osteotomy. The present study introduced a novel secondary groove osteotomy technique that uses a unique approach to talar medial and central osteochondral lesions and approximately $90 \%$ of the patients showed excellent outcomes in our study over the long-term follow-up period.

Historically, Wallen and Fallat ${ }^{[15]}$ first described the crescentic osteotomy, but that technique restricts perpendicular access to the talar dome. Sammarco and Makwana ${ }^{[16]}$ reported a technique in which a five-sided bone block with a rectangular base was temporarily removed. Siegel and Mount ${ }^{[17]}$ described a step cut osteotomy and highlighted the importance of the stability of osteotomy sites during rehabilitation. Draper and Fallat ${ }^{[18]}$ reported a V-shaped osteotomy in medial talar lesions, which yielded good exposure to the lesions.

Malunion or nonunion of the malleolar osteotomy or the avascular necrosis of the bone block may be the potential complications of this procedure. In this study, no malunion, nonunion, or avascular necrosis was present. We think that predrilling the medial malleolus before the osteotomy minimized the risk for this complication. Mendicino et al. ${ }^{[19]}$ reported no nonunion or malunion cases in a case series of individuals who underwent oblique osteotomy. Kreuz et al. ${ }^{[10]}$ reported promising results of a new technique that described a four-sided bone pyramid in a differently shaped block. No avascular necrosis was reported.

Most previous studies used the classic transmalleolar approach. ${ }^{[5,6,8,9]}$ Van Bergen et al. ${ }^{[20]}$ evaluated the optimal osteotomy direction in 45 patients using computed tomography and plain radiographs. The authors emphasized that the direction of a medial malleolar osteotomy should be at a mean angle of $30^{\circ}$ relative to the tibial axis, which will likely result in a congruent joint after reduction. Based on their findings, they concluded that the risk for malunion would be lowered after the reduction. Our technique used an oblique osteotomy at an angle of approximately $30^{\circ}$ to the tibial axis, and no malunion was observed.
Imhoff et al. ${ }^{[5]}$ emphasized the relevance of having had a previous surgery with negative clinical outcomes. In contrast, Kreuz et al. ${ }^{[10]}$ described good midterm results in 35 patients treated with OAT after the failure of primary arthroscopic management. However, the limitations of that study were that it did not report the time span between the two operations and did not use comparable groups of individuals. Haasper et al. ${ }^{[21]}$ found no difference between previously treated and untreated patients in the midterm period. Park et al. ${ }^{[22]}$ compared clinical outcomes among patients with large OLT who received primary OAT versus those who received secondary OAT after failure of marrow stimulation and found no differences between groups. In our series, four secondary patients $(19 \%)$ had previous surgeries. In this small group, there were two (50\%) complications, one of which resulted in arthrodesis, and the other was treated with ankle arthroscopic debridement because of ankle impingement.

Potential donor site morbidity is challenging in OAT of the talus. In their studies, Valderrabano et al. ${ }^{[9]}$ and Paul et al. ${ }^{[23]}$ discussed donor site morbidity. Paul et al. ${ }^{[23]}$ evaluated donor site morbidity in a very large patient group (112 patients with a 55-month follow-up period), and they reported no correlation between the number of grafts, the size of the grafts, the age of the patients and the functional scores of the knees. However, Baltzer and Arnold ${ }^{[24]}$ found persistent knee pain in only $2 \%$ of patients. In the study of Valderrabano et al., ${ }^{[9]}$ the ratio of donor site morbidity was $50 \%$, which is one of the highest ratios in the literature. Garretson et al. ${ }^{[25]}$ evaluated pressure dispersion in the patellofemoral joint at osteochondral donor sites. The authors concluded that the best location for the donor site was proximal to the sulcus terminalis of the lateral femoral condyle. Fraser et al. ${ }^{[26]}$ evaluated the donor site of 39 patients undergoing OAT by MRI and indicated that the rate of donor site morbidity was $12.5 \%$ at 24 months postoperatively. In the present study, $14 \%$ of the patients suffered from persistent knee pain at the end of the first year. However, no patients required additional treatment after one year.

There are some limitations to our study. The retrospective design of the study, small number of patients and lack of a comparison group lowered the statistical power of our study. Furthermore, our group of patients was not homogeneous. Two patients who had previous surgeries might have affected the clinical outcomes. Also, we compared the results according to clinical scoring systems. Second-look arthroscopy or Magnetic Resonance Observation of 
Cartilage Repair Tissue (MRI grading system) was not used routinely.

In conclusion, in the present study, good to excellent results were obtained in the treatment of OLT with OAT with a novel malleolar osteotomy technique for a minimum follow-up duration of 10 years and over. The additional use of the groove osteotomy technique may simplify the challenging surgery procedure. Osteochondral autograft transfer is a good option in OLT.

\section{Declaration of conflicting interests}

The authors declared no conflicts of interest with respect to the authorship and/or publication of this article.

\section{Funding}

The authors received no financial support for the research and/or authorship of this article.

\section{REFERENCES}

1. Eren TK, Ataoğlu MB, Eren A, Geylan DE, Öner AY, Kanatlı U. Comparison of arthroscopic microfracture and cell-free scaffold implantation techniques in the treatment of talar osteochondral lesions. Eklem Hastalik Cerrahisi 2019;30:97-105.

2. Murawski CD, Kennedy JG. Operative treatment of osteochondral lesions of the talus. J Bone Joint Surg [Am] 2013;95:1045-54.

3. Kiliç A, Kabukçuoğlu Y, Gül M, Ozkaya U, Sökücü S. Early results of open mosaicplasty in osteochondral lesions of the talus. Acta Orthop Traumatol Turc 2009;43:235-42.

4. Hangody L, Füles P. Autologous osteochondral mosaicplasty for the treatment of full-thickness defects of weight-bearing joints: ten years of experimental and clinical experience. J Bone Joint Surg [Am] 2003;85 Suppl 2:25-32.

5. Imhoff AB, Paul J, Ottinger B, Wörtler K, Lämmle L, Spang $\mathrm{J}$, et al. Osteochondral transplantation of the talus: longterm clinical and magnetic resonance imaging evaluation. Am J Sports Med 2011;39:1487-93.

6. Lee $\mathrm{CH}$, Chao $\mathrm{KH}$, Huang GS, Wu SS. Osteochondral autografts for osteochondritis dissecans of the talus. Foot Ankle Int 2003;24:815-22.

7. Gianakos AL, Yasui Y, Hannon CP, Kennedy JG. Current management of talar osteochondral lesions. World J Orthop 2017;8:12-20.

8. Hangody L, Dobos J, Baló E, Pánics G, Hangody LR, Berkes I. Clinical experiences with autologous osteochondral mosaicplasty in an athletic population: a 17-year prospective multicenter study. Am J Sports Med 2010;38:1125-33.

9. Valderrabano V, Leumann A, Rasch H, Egelhof T, Hintermann B, Pagenstert G. Knee-to-Ankle Mosai cplasty for the Treatment of Osteochondral Lesions of the Ankle Joint. Am J Sports Med 2009;37(1_suppl):105S-11S.

10. Kreuz PC, Steinwachs M, Erggelet C, Lahm A, Henle P, Niemeyer P. Mosaicplasty with autogenous talar autograft for osteochondral lesions of the talus after failed primary arthroscopic management: a prospective study with a 4-year follow-up. Am J Sports Med 2006;34:55-63.

11. Hepple S, Winson IG, Glew D. Osteochondral lesions of the talus: a revised classification. Foot Ankle Int 1999;20:789-93.

12. Takakura Y, Tanaka Y, Kumai T, Tamai S. Low tibial osteotomy for osteoarthritis of the ankle. Results of a new operation in 18 patients. J Bone Joint Surg [Br] 1995;77:50-4.

13. Guney A, Yurdakul E, Karaman I, Bilal O, Kafadar IH, Oner M. Medium-term outcomes of mosaicplasty versus arthroscopic microfracture with or without platelet-rich plasma in the treatment of osteochondral lesions of the talus. Knee Surg Sports Traumatol Arthrosc 2016;24:1293-8.

14. Hangody L, Kish G, Módis L, Szerb I, Gáspár L, Diószegi $\mathrm{Z}$, et al. Mosaicplasty for the treatment of osteochondritis dissecans of the talus: two to seven year results in 36 patients. Foot Ankle Int 2001;22:552-8.

15. Wallen EA, Fallat LM. Crescentic transmalleolar osteotomy for optimal exposure of the medial talar dome. J Foot Surg 1989;28:389-94.

16. Sammarco GJ, Makwana NK. Treatment of talar osteochondral lesions using local osteochondral graft. Foot Ankle Int 2002;23:693-8.

17. Siegel SJ, Mount AC. Step-cut medial malleolar osteotomy: literature review and case reports. J Foot Ankle Surg 2012;51:226-33.

18. Draper SD, Fallat LM. Autogenous bone grafting for the treatment of talar dome lesions. J Foot Ankle Surg 2000;39:15-23.

19. Mendicino RW, Lee MS, Grossman JP, Shromoff PJ. Oblique medial malleolar osteotomy for the management of talar dome lesions. J Foot Ankle Surg 1998;37:516-23.

20. van Bergen CJ, Tuijthof GJ, Sierevelt IN, van Dijk CN. Direction of the oblique medial malleolar osteotomy for exposure of the talus. Arch Orthop Trauma Surg 2011;131:893-901.

21. Haasper C, Zelle BA, Knobloch K, Jagodzinski M, Citak $\mathrm{M}$, Lotz J, et al. No mid-term difference in mosaicplasty in previously treated versus previously untreated patients with osteochondral lesions of the talus. Arch Orthop Trauma Surg 2008;128:499-504.

22. Park KH, Hwang Y, Han SH, Park YJ, Shim DW, Choi WJ, et al. Primary Versus Secondary Osteochondral Autograft Transplantation for the Treatment of Large Osteochondral Lesions of the Talus. Am J Sports Med 2018;46:1389-96.

23. Paul J, Sagstetter A, Kriner M, Imhoff AB, Spang J, Hinterwimmer S. Donor-site morbidity after osteochondral autologous transplantation for lesions of the talus. J Bone Joint Surg Am 2009;91:1683-8.

24. Baltzer AW, Arnold JP. Bone-cartilage transplantation from the ipsilateral knee for chondral lesions of the talus. Arthroscopy 2005;21:159-66.

25. Garretson RB 3rd, Katolik LI, Verma N, Beck PR, Bach BR, Cole BJ. Contact pressure at osteochondral donor sites in the patellofemoral joint. Am J Sports Med 2004;32:967-74.

26. Fraser EJ, Savage-Elliott I, Yasui Y, Ackermann J, Watson G, Ross KA, et al. Clinical and MRI Donor Site Outcomes Following Autologous Osteochondral Transplantation for Talar Osteochondral Lesions. Foot Ankle Int 2016;37:968-76. 